Journal of Advanced Research in Fluid Mechanics and Thermal Sciences

\title{
Review of Factors Affecting the Phase-Redistribution in the Branching T- Junction
}

\author{
Faheem Ejaz ${ }^{1}$, William Pao $^{1,}{ }^{*}$, Mohammad Shakir Nasif ${ }^{1}$ \\ 1 Department of Mechanical Engineering, Universiti Teknologi PETRONAS, Seri Iskandar 32610, Malaysia
}

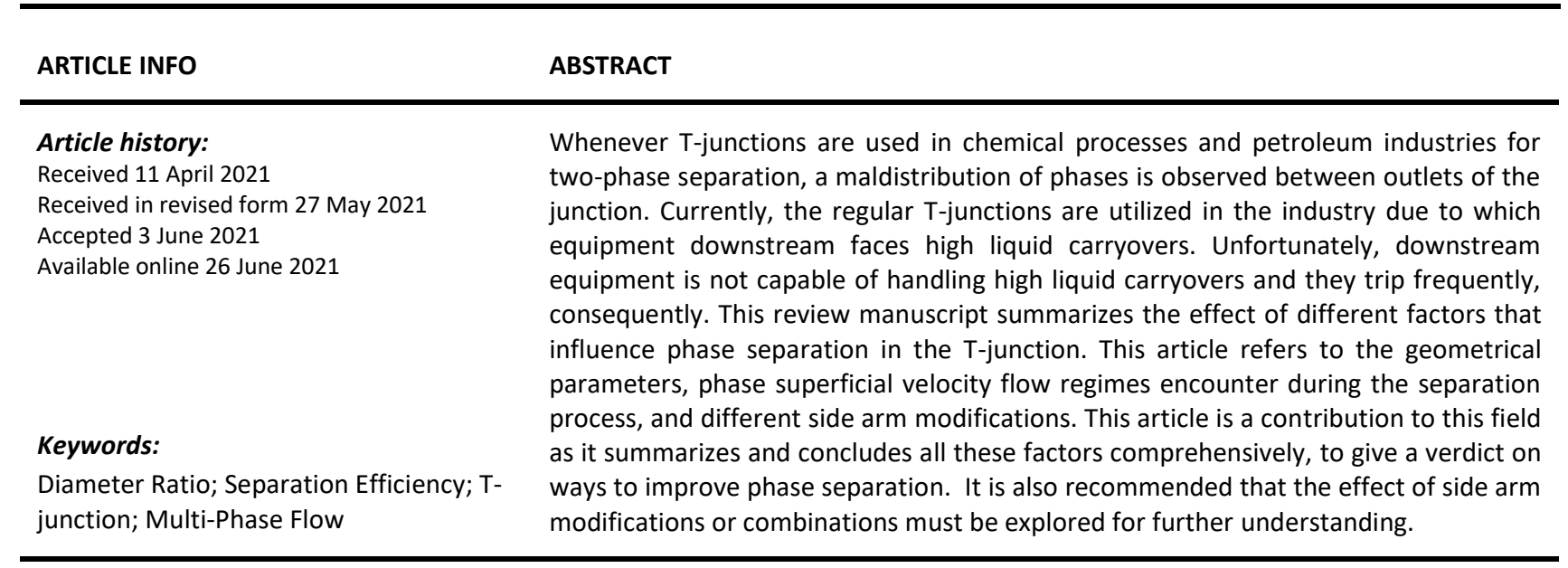

\section{Introduction}

In petroleum, chemical industries and heat exchanger applications, gas extracted from the wells is utilized for power generation [1,2]. In terms of heat transfer applications, the heat transfer phenomenon was also studied by researchers in the past [3-5]. Gas separation is carried out with the support of a T-junction [6]. Industries currently are using regular T-junction and do not contemplate the incoming flow regime and side arm diameter, leading to unnecessary liquid takeoffs. The excessive liquid also lessens the efficiency of the gas scrubber to separate gas and liquids. Therefore, downstream equipment faces frequent tripping because it is not designed for such high liquid carryovers [6-8]. It is evident that tripping or shutdowns can cost the loss of time and money. A study on turbines has been reviewed in the past [9].

Multiphase separation is the need of the petroleum and chemical industries. Some use Biomass as fuel and some use gas extracted from the wells for power generation [10]. While separating crude oil from the wells, a multiphase mixture of water, gas, oil, solids and minerals is produced [11,12]. Tjunctions are employed along with gas scrubbers to facilitate phase separation. However, it is very

\footnotetext{
* Corresponding author.

E-mail address: william.pao@utp.edu.my
}

https://doi.org/10.37934/arfmts.84.1.6077 
difficult to seamlessly predict the multiphase separation. As reported by many researchers $[11,13-$ 16], Orange [17] was the very first researcher who observed and working on the maldistribution of phases at different piping junctions in 1973. Yang et al., [18] in their review paper showed all possible influential parameters in a pie chart for comparison. He addressed the geometry of the T-junction as the most influential parameter above all. This is the reason that it has been the point of concern for a bunch of researchers in the past. As discussed by Wren [19] and Liang [20], there are eight parameters that can affect phase separation, such as liquid and gas velocities, diameter of the side arm, run arm and main arm, the inclination of side arm, the inclination of run arm and radius of curvature of the edge at which side arm is attached to the main arm. These parameters have been analyzed by many researchers [6,21-26].

The data is scattered around, and several theories were presented in the past to study the effect of different parameters on phase separation. However, a comprehensive review is required to cover up the studies reported in the past few decades. This manuscript intended to fill in the gap by addressing different factors' influence on phase separation by reviewing different prominent studies. The influence of different parameters was studied separately for better understanding. This manuscript further summarized the influence of each variable on phase separation.

\section{Literature Review}

As we know, petroleum industries' matter of concern is the multiphase flow separation and most importantly two-phase separation. T-junction is commonly used as a partial phase separator [14,20,27-29]. This drives many researchers to work on this and to enhance separation efficiency. However, this type of study is nothing new, but it dates to the 20th Century. Before going for an indepth analysis of previous research, it is obligatory to discuss T-junction geometry and types. In general, four different types of two-phase flow are as follows

- Liquid-Gas Flow

This flow is usually found in refrigeration and air conditioning and power sectors.

- Solid-Gas Flow

This type of flow comprises of solid transmission within a gaseous agent.

- Solid-Liquid Flow

This flow deals with the flow of solids along with any type of liquid.

- Multiple-Liquid Flow

This flow type normally deals with two types of liquids that cannot be mixed.

For the time being, the liquid-gas flow is deemed since it is widely used in industrial application and is one of the main concerns where there is a question about the lifetime or maintenance cost of the downstream equipment. An important factor we need to contemplate is how two-phase liquidgas flow propagates within a pipe geometry when there is a constant mixing of both phases. The twophase flow nature relies upon the velocity of individual liquid and gas phases and the orientation of the pipe in which the flow is propagating [30]. The most prominent flow patterns are shown in Figure 1. 


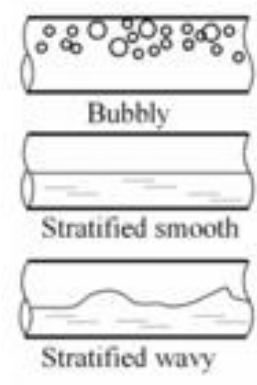

Fig. 1. Flow patterns in the horizontal flow [49]

\subsection{T-Junction}

T-junction, because of its simple design is utilized as a partial phase separator. It consists of two intersecting pipes. Although the general type of T-junction has perpendicular intersecting pipes other angles of inclinations have also been used in history. Figure 2 illustrates a branching T-junction schematic diagram.

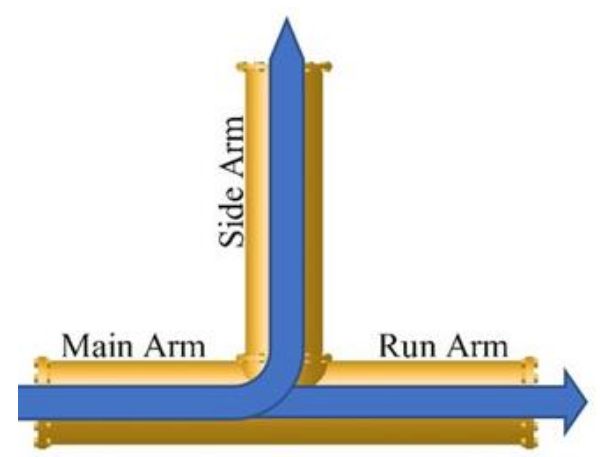

Fig. 2. Regular T-Junction

\subsection{Types of T-Junction}

There are usually two types of T-junctions depending upon the flow of the fluid streams [18].

\subsubsection{Branching T-junction}

In branching T-junction, the flow comes from the main arm and further divides into two different outlets (run arm and side arm). The flow separation occurs in the center of the junctions.

\subsubsection{Impacting T-Junction}

As the name suggests, the fluid stream uses side arm as an inlet and puts up an impact on the wall of the main wall and divides to both sides of the pipe. The region of the impact is usually right after the fluid passes through the junction. In Figure 3, the schematic diagram is shown for a better understanding. 


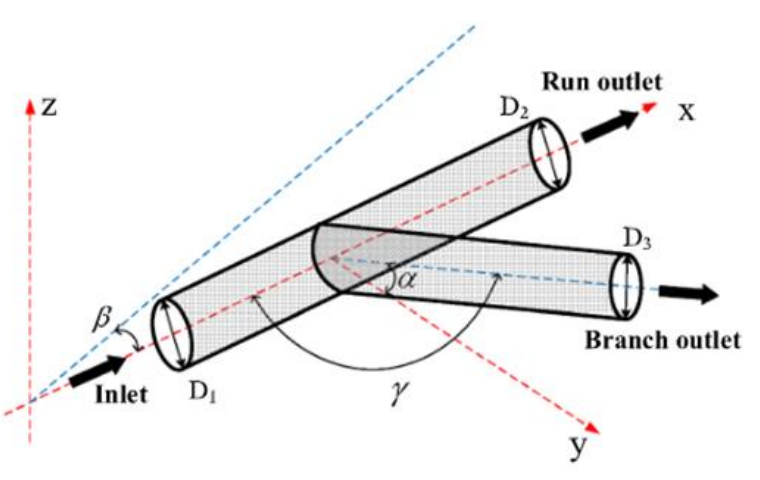

(a)

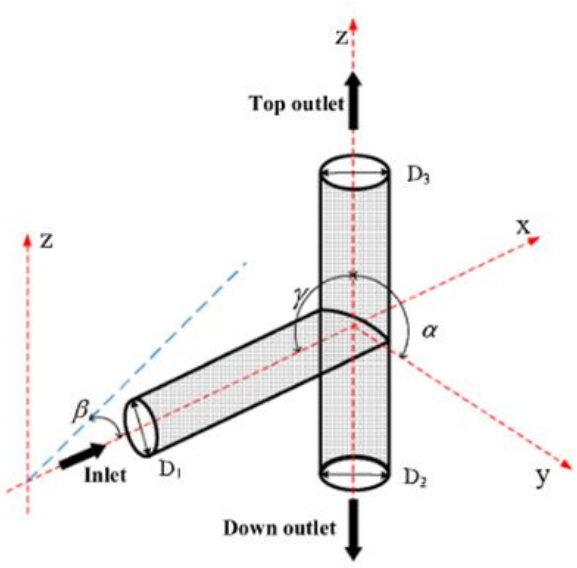

(b)

Fig. 3. Schematic Diagram of (a) Branching T-junction (b) Impacting T-Junction [18]

Whereas D1, D2, D3 = Diameter of the main arm, run arm and side arm respectively, $\alpha=$ Angle between side arm to the horizontal plane, $\beta=$ Angle between the main arm to the horizontal plane, $\gamma=$ Angle between side arm and main arm. Yang et al., [18] in their paper has summarized the context for the study of T-Junction. It can be seen from Figure 4 that even though T-junction is the simplest in its geometry, it requires much more attention. The separation efficiency of the T-junction will be dependent on multiple factors.

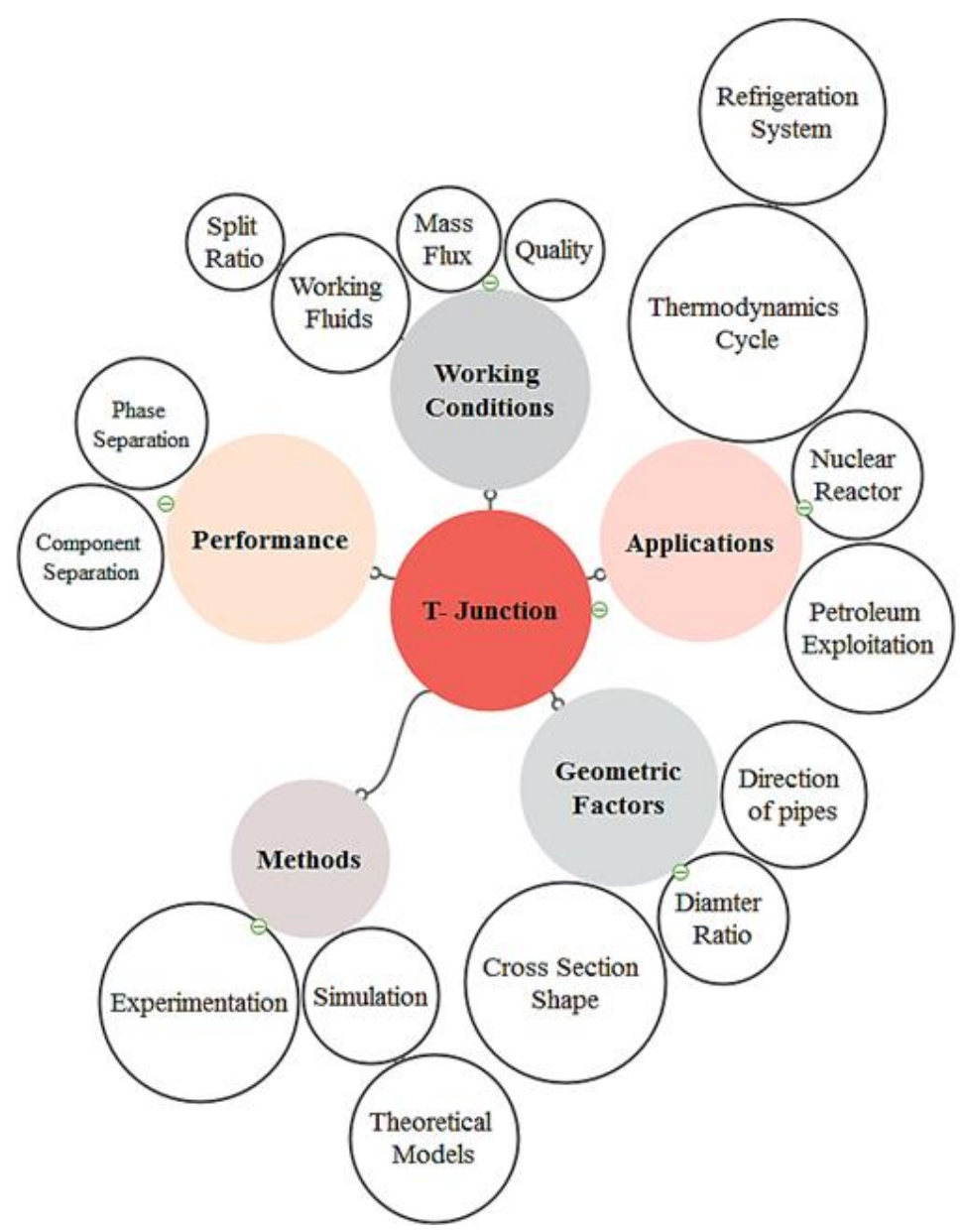

Fig. 4. Framework proposed by Yang et al., Redrwan [18] 


\subsection{Criteria to Represent Phase Split Data}

Baker [30] mentioned the most suitable criteria which can help us predict the locus point of the separation data on the $x-y$ plot. Although there are numerous methods to depict the phase split data this one got its significance.

To further add, Azzopardi [6] mentioned an expression suitable to measure phase separation. As we know, perfect separation is achieved when only one phase comes out of the side arm and one from the run arm. So, if we would plot these points on Baker's graph it would be at $y=0, x=1$ or $y=1$, $x=0$. So, one way to demonstrate the extent of the separation is by getting the difference of the achieved points to these points.

$S=\sqrt{\left(1-G^{\prime}\right)^{2}+L^{\prime 2}}$

whereas,

$G^{\prime}=$ Fraction of Gas in the side outlet

$L^{\prime}=$ Fraction of Liquid in the side outlet

In Figure 5, if the phase split up data lie on the diagonal line, it means there is equal phase separation. Further away the points are to the diagonal line, better would be the separation. As shown in Figure 6, gas-rich stream data will be below the diagonal line (Equal split line) and liquidrich stream data will be above the line. Hence, for the T-junction to function better, the phase split data points should be closer to the $x$-axis i.e., the liquid taken off from the side arm should be lower than gas taken off from the same arm. Whereas " $F_{G}$ " represents the gas fraction taken off in the side outlet and " $\mathrm{F}_{\mathrm{L}}$ " portrays the liquid fraction taken off in the same arm.

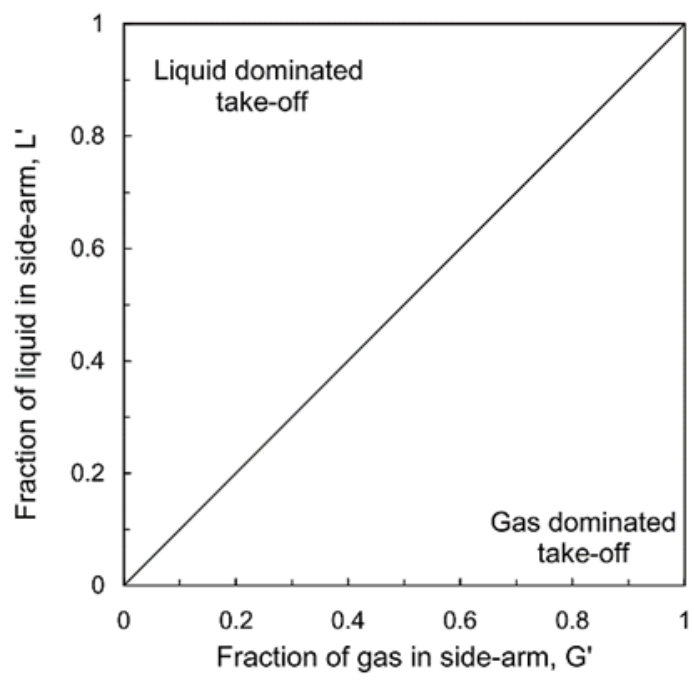

Fig. 5. Representation of phase split in a Tjunction [30]

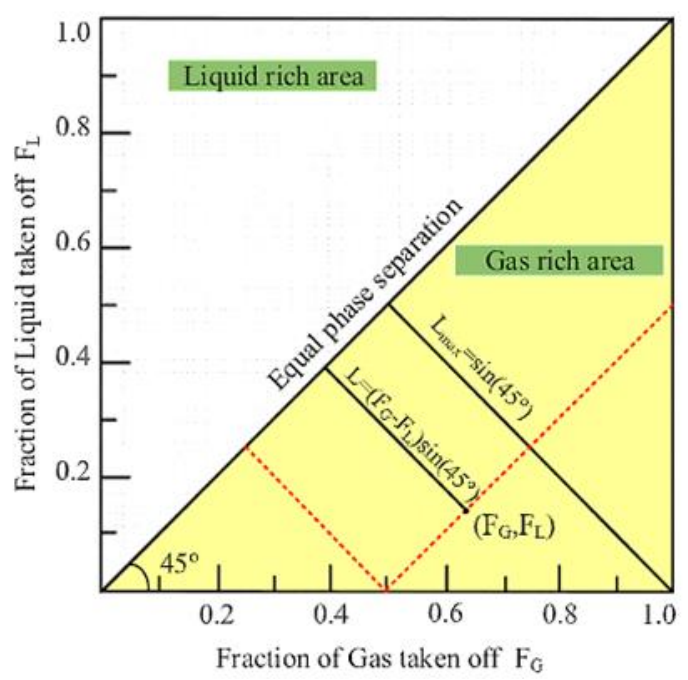

Fig. 6. Two-Phase separation plot for Tjunction [18] 


\subsection{Parameters Influencing Phase Separation in The Branching T-Junction}

The research will be dedicated on branching T-junction with a vertical side arm. Literature is full of different experimental and numerical analysis for different parameters tweaking. The literature is divided into the following categories.

- Influence of the geometry on the Phase separation efficiency

- Influence of angle of inclination of the side arm

- Influence of diameter ratio

- Influence of superficial velocities of gas and liquid at the inlet

- Influence of flow regime

- Modified T-junction and Series and parallel combinations

\subsubsection{Influence of T-junction geometry}

The geometry of a T-junction is so far the most influential parameter on the phase separation efficiency. Even though the majority of literature is based on the geometry of T-junction, there is still room to work around the parameters because of the seriousness of the issue $[11,19,31,32]$.

\subsubsection{Influence of angle of inclination of the side arm}

As mentioned by Chen et al., [33], (Figure 7) the phase distribution depends on the angle of inclination of the side arm from the main arm. Investigated flow regimes were slug flow, annular flow, and annular-slug flows. The main arm used was horizontal and side arm having angles of inclination from $30 \mathrm{o}$ to $150 \mathrm{o}$ with the main arm. For the accurate estimation of flow patterns, a highspeed camera was employed for better results.

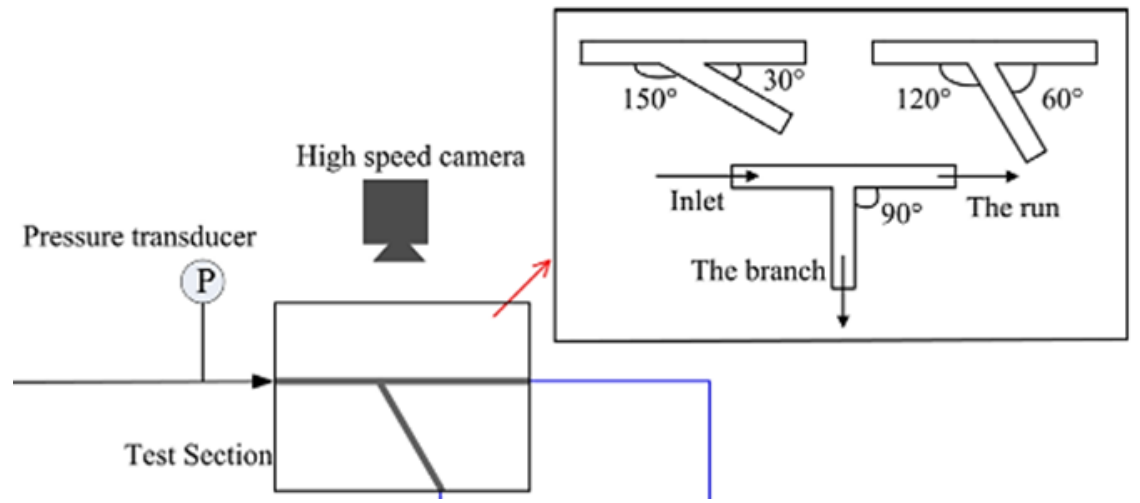

Fig. 7. Side arm inclinations used by Chen et al., [33]

In Figure 8, it is seen that for slug flow, the higher the inclination angle higher would be the phase separation. He clarified the reason, as we increase the angle, the fluid tends to keep flowing in the main arm because of inertia and it will be less likely for it to turn to go to the side arm. In contrast, Figure 9 indicates lower phase separation for annular flow. The reason being, a secondary flow streamline is generated at the opposite wall of the junction, forcing the liquid to fall to the side arm. But for higher branch angles, it is difficult for the liquid stream to take a turn due to the inertia effect. Hence the separation efficiency will be higher for higher angles of inclination. 


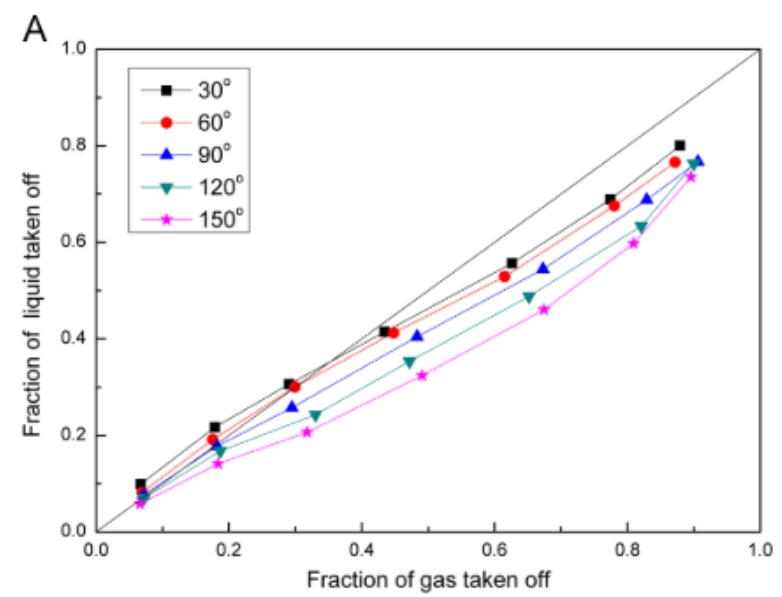

Fig. 8. Effect of side arm inclination on phase separation (Annular Flow) [33]

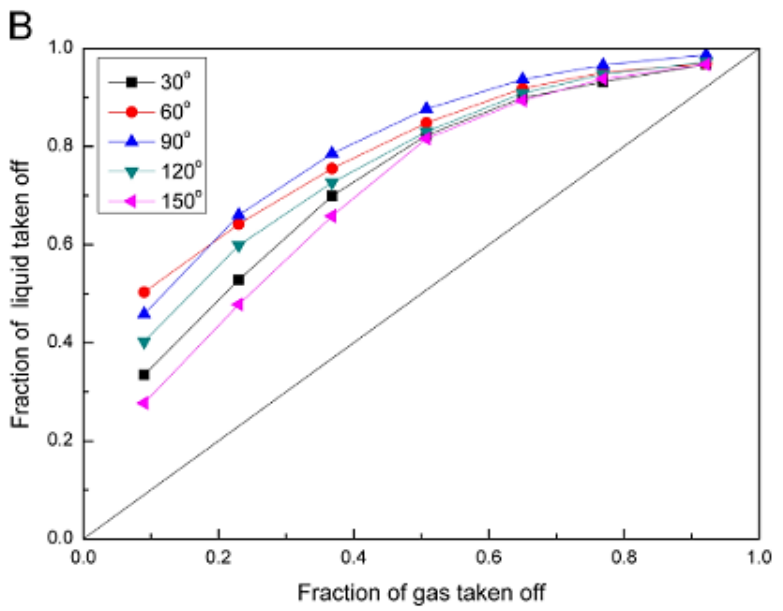

Fig. 9. Effect of side arm inclination on phase separation (Annular Flow) [33]

Another study by Hong [16] revealed the influence of side arm inclination. He used side arm inclination from $+90^{\circ}$ to $-90^{\circ}$. In his research, he revealed that for side arm vertically upward i.e. $+90^{\circ}$, liquid taken off to the side arm significantly reduces due to gravitational force acting on the liquid and inertia which forces the liquid to stay in the main arm (Figure 10). By decreasing the angle of inclination, the percentage of liquid taken off to the side arm of the junction starts to increase and it is most prominent when it is -900 i.e. vertically downward side arm.

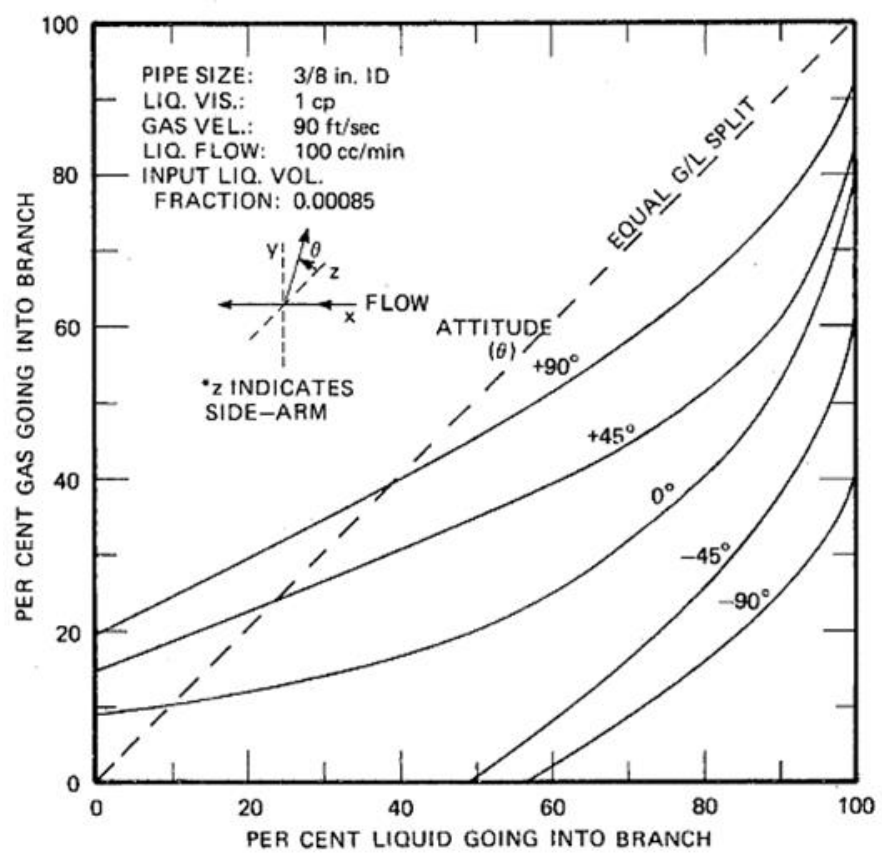

Fig. 10. Influence of side arm orientation on Phase separation [16]

Martit and Shoham et al., [21] examined the influence of side arm inclination for stratified wavy flow. In T-junction, he used vertical run arm and a horizontal side arm. Whereas the side arm was inclined at $-5^{\circ},-10^{\circ},-25^{\circ},-40^{\circ}$ and vertically upward at $1^{\circ}, 5^{\circ}, 10^{\circ}, 20^{\circ}$ (Figure 11 and 12 ). From the graphs, for negative inclination the gravitational force effect comes into place, increasing the 
liquid take off through the branch as compared to upward inclination. However, for positive inclinations i.e. upward side arm, liquid flow to the run arm as a priority due to gravitational pull.

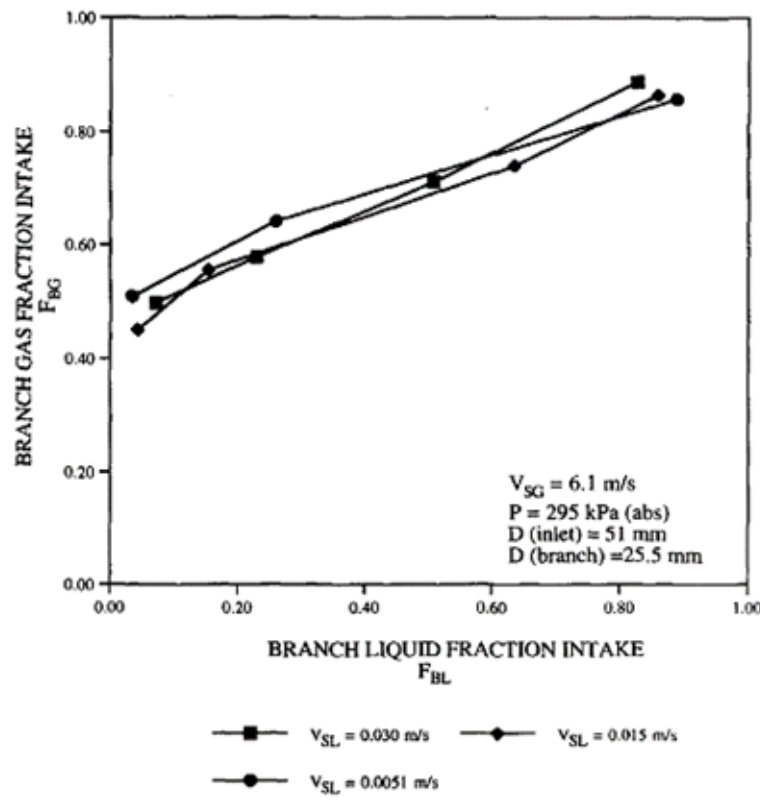

Fig. 11. Splitting Ratio for $+20^{\circ}$ upward side arm [21]

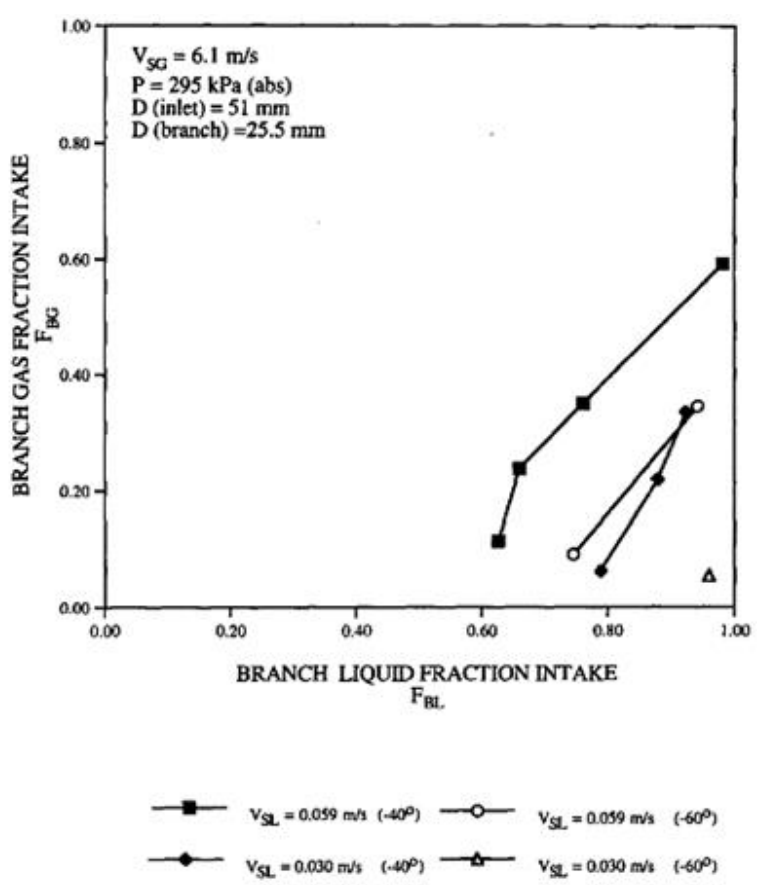

Fig. 12. Splitting Ratio for $-40^{\circ}$ and $-60^{\circ}$ downward side arm [21]

\subsubsection{Influence of diameter ratio}

Figure 13 shows the regular and reduced T-junction. In regular T-junctions, the diameter of the side arm and main are equal whereas, in reduced T-junction, the diameter of the side arm is less than the main arm. The ratio between side arm diameters to the main arm diameter is known as the "Diameter Ratio". Some of the researchers worked on regular T-junction [16,24,34-37] and reduced junction $[22,38-41]$.

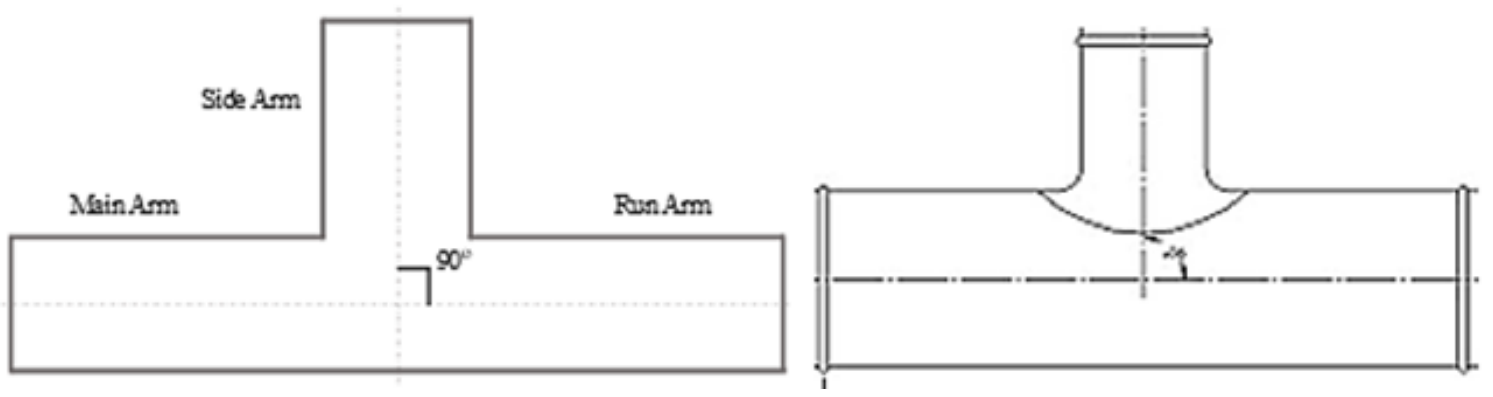

Fig. 13. Regular and Reduced T-junction

Azzopardi [23] studied the effect of diameter ratio on phase separation for stratified and annular flow. He used two T-junctions for comparison.

- $1^{\text {st }} T$ - Junction: $D_{1}, D_{2}, D_{3}=0.125 \mathrm{~m}$

- $\quad 2^{\text {nd }}$ T-junctions: $D_{1}, D_{2}=0.125, D_{3}=0.076 m$ 
It can be noticed from the graphical representation that, decreasing the side arm diameter results in higher separation efficiency. As shown in Figure 14, the black squares represent a regular Tjunction which has higher liquid take off in the side arm.

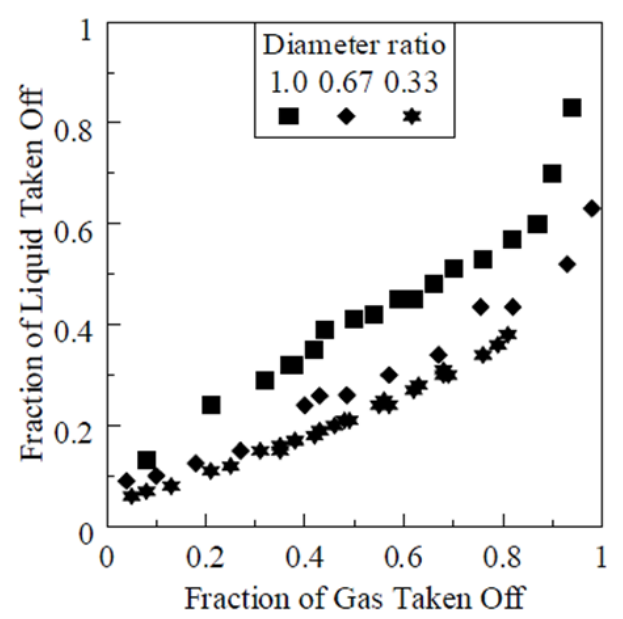

Fig. 14. Influence of Diameter ration on phase separation (Annular Flow) [23]

Hart et al., [42] in their study used $D_{1}, D_{2}=0.051 m$ and $D_{3}=0.025$ on stratified wavy and annular flow. It was found that in the case of reduced T-junction according to continuity equation speed of gas increases in the side arm, due to which pressure drop occurs between a side arm and main according to Bernoulli's equation. This pressure drop encourages liquid take-off. It was also found that if the liquid is moving axially within the main arm, even a small amount of pressure difference is more than enough to lift the liquid to the side arm. But when the inertia comes into play, at high momentum very high pressure would be required to move the liquid to the side arm [42] (Figure 15).

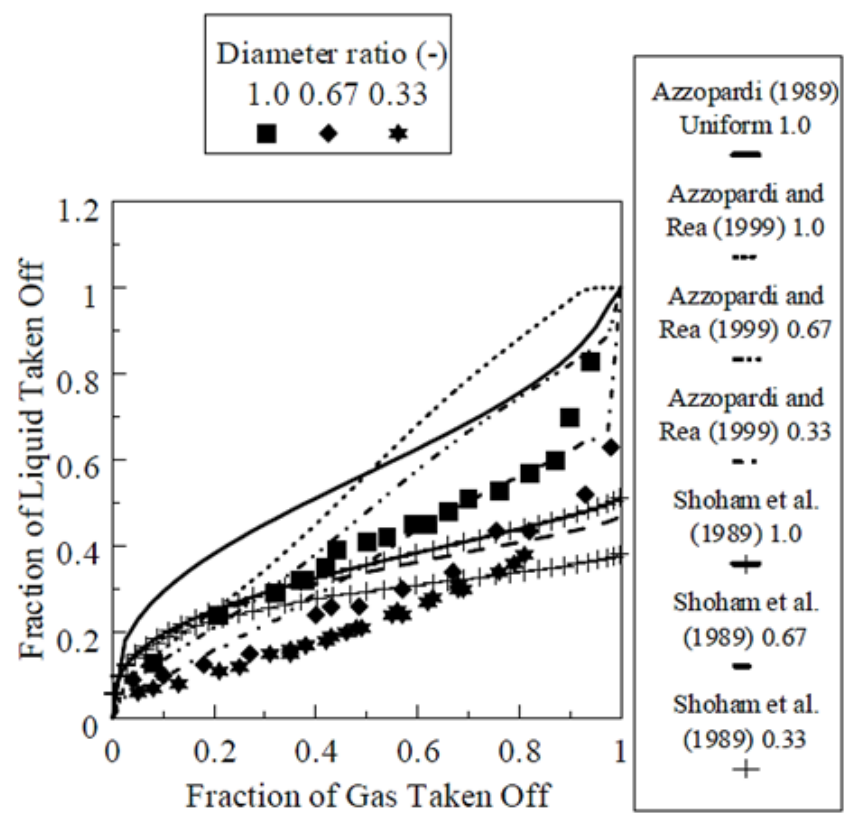

Fig. 15. A comparison conducted by Azzopardi [23] for different diameter ratios 
Saieed et al., [43] studied the effect of the diameter ratio for phase split recently comparing results with other researchers. The flow regime is taken into consideration as a stratified wavy flow (Figure 16). In his study he revealed that the most obvious fact that most of the researchers believe till now that decreasing the diameter ratio always increases the separation efficiency is true.

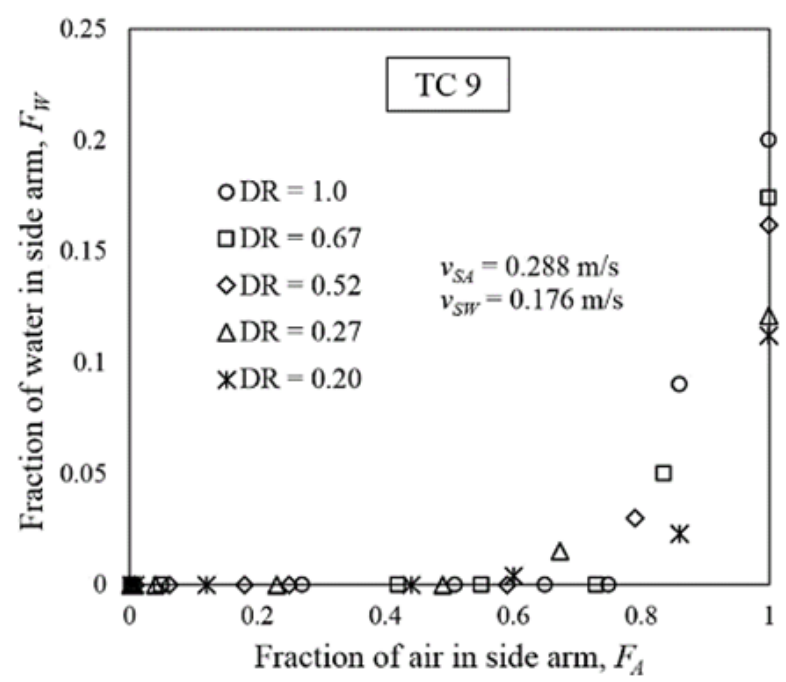

Fig. 16. Phase split data for different diameter ratios [43]

It is clearly seen that decreasing the diameter ratio increases the phase separation. However, for lower superficial velocities the difference is not noticeable but for higher superficial velocities lower diameter ratio $\mathrm{T}$-junction produced promising results. The effect of diameter ratio is the most investigated parameter yet among others. A detailed review was given by Ejaz et al., [44] addressing critical findings in 1998 and state of the art theories that, diameter ratio improves phase separation but up to a certain limit. For instance, Saieed et al., [43] identified that 0.67 diameter ratio performed better than other diameter ratio T-junctions.

\subsubsection{Influence of liquid and gas superficial velocities}

Superficial velocities of gas and liquid play an important role in the phase separation because whenever there is a fluid stream moving, it has some inertia and momentum which can resist or support separation. Al Azizi [14] in his experimental investigation found that increasing the liquid superficial velocity results in prominent phase separation. Because as the liquid velocity increases its momentum and inertia increase. Due to higher inertia, it is less evident to have liquid take-offs into the side arm.

Das et al., [45] utilized a simple T-junction to study the effect of the superficial velocity of both phases on the phase redistribution. As seen from the Figure 17 and 18, it can be concluded that as we increase gas superficial velocity, the liquid fraction at the side arm increases significantly due to more pressure drop. In contrast, for the low liquid superficial velocities, the points are closer or a little above the equal split line which means that at lower velocity liquid has lower inertia, so it gets pulled out from the side arm by pressure drop. However, for higher liquid velocities a better phase separation was witnessed. 

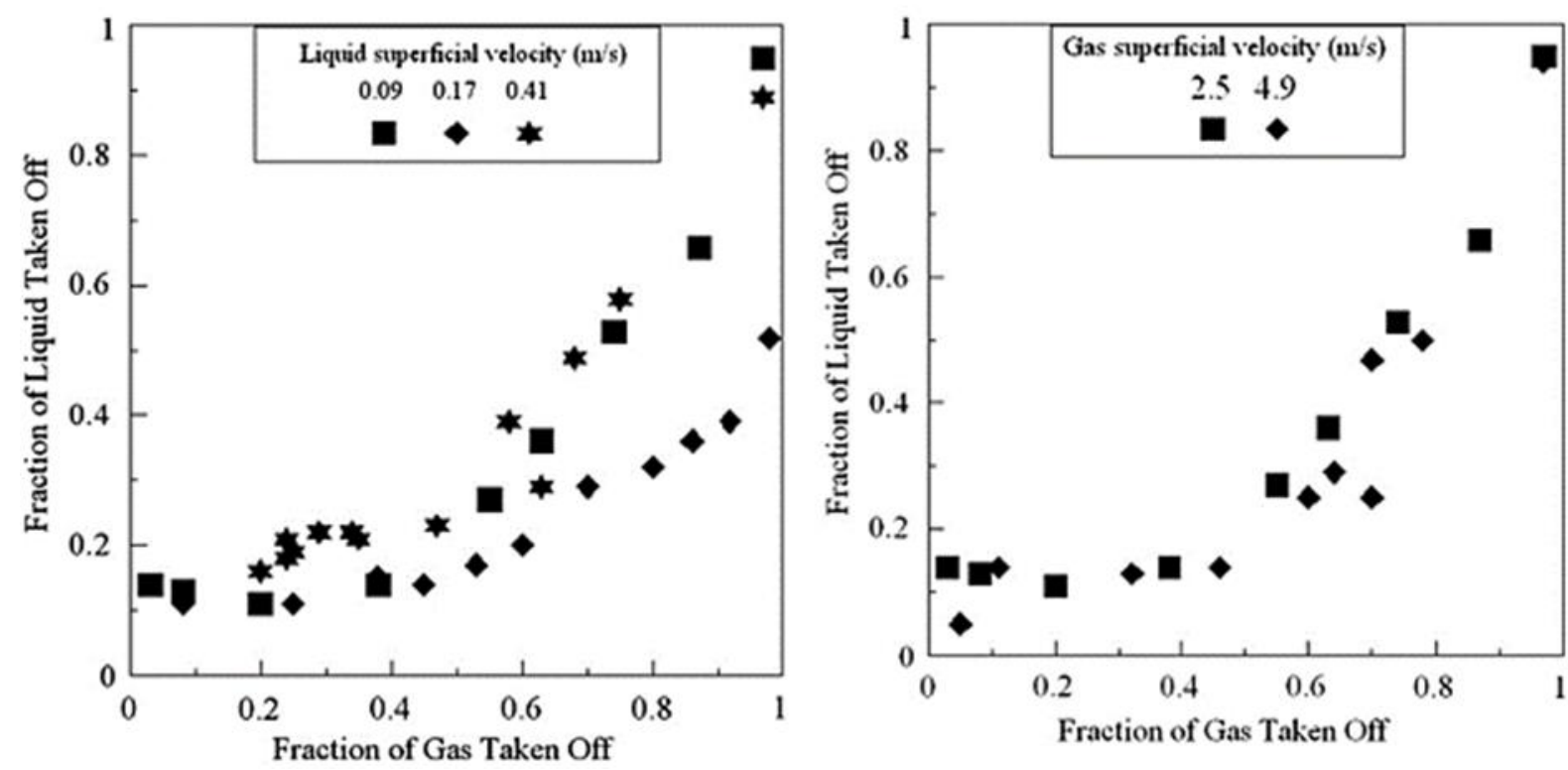

Fig. 17. Effect of liquid and gas superficial velocities on phase separation [14]

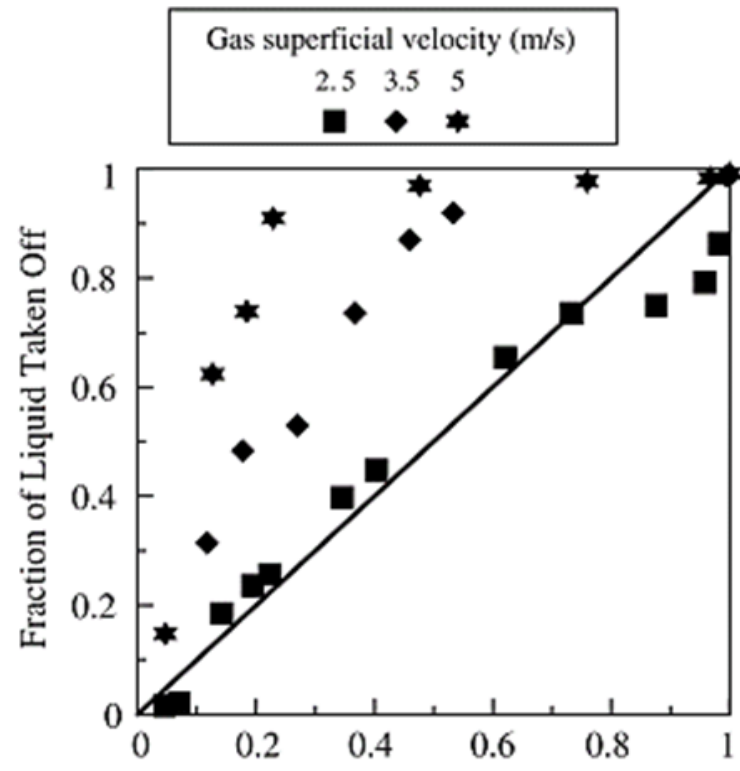

(a)

Fraction of Gas Taken Off

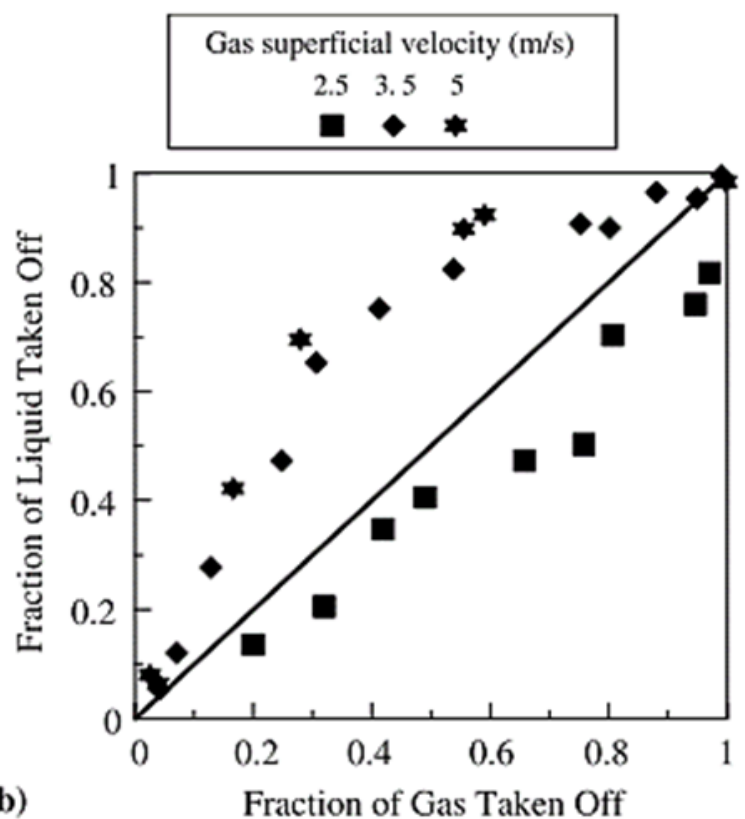

Fig. 18. Influence of gas superficial velocity and liquid superficial velocity of (a) $0.0055 \mathrm{~m} / \mathrm{s}$ (b) 0.0097 $\mathrm{m} / \mathrm{s}[45]$

Saieed et al., [43] identified a term called "liquid carryover threshold" and defined as the "minimum gas fraction at the side arm at which the liquid starts to take off". He then correlated the relation between liquid carryover threshold and superficial velocities of both phases.

They examined phase superficial velocities for different diameter ratios to further analyze the data. To study liquid superficial velocity, they kept gas superficial velocity constant at $0.228 \mathrm{~m} / \mathrm{s}$. whereas, to analyze air superficial velocity influence, water superficial velocity was kept constant at $0.094 \mathrm{~m} / \mathrm{s}$. As seen from the Figure 19, increasing the liquid superficial velocity tends to decrease the liquid carryover threshold. It is noticeable that decreasing the diameter ratio decreases the overall threshold of the liquid carryover. Whereas for higher liquid superficial velocity, liquid carryover 
threshold decreases again because for higher air velocities pressure drop occurs and liquid takes off from the side arm easily at lower liquid superficial velocities.
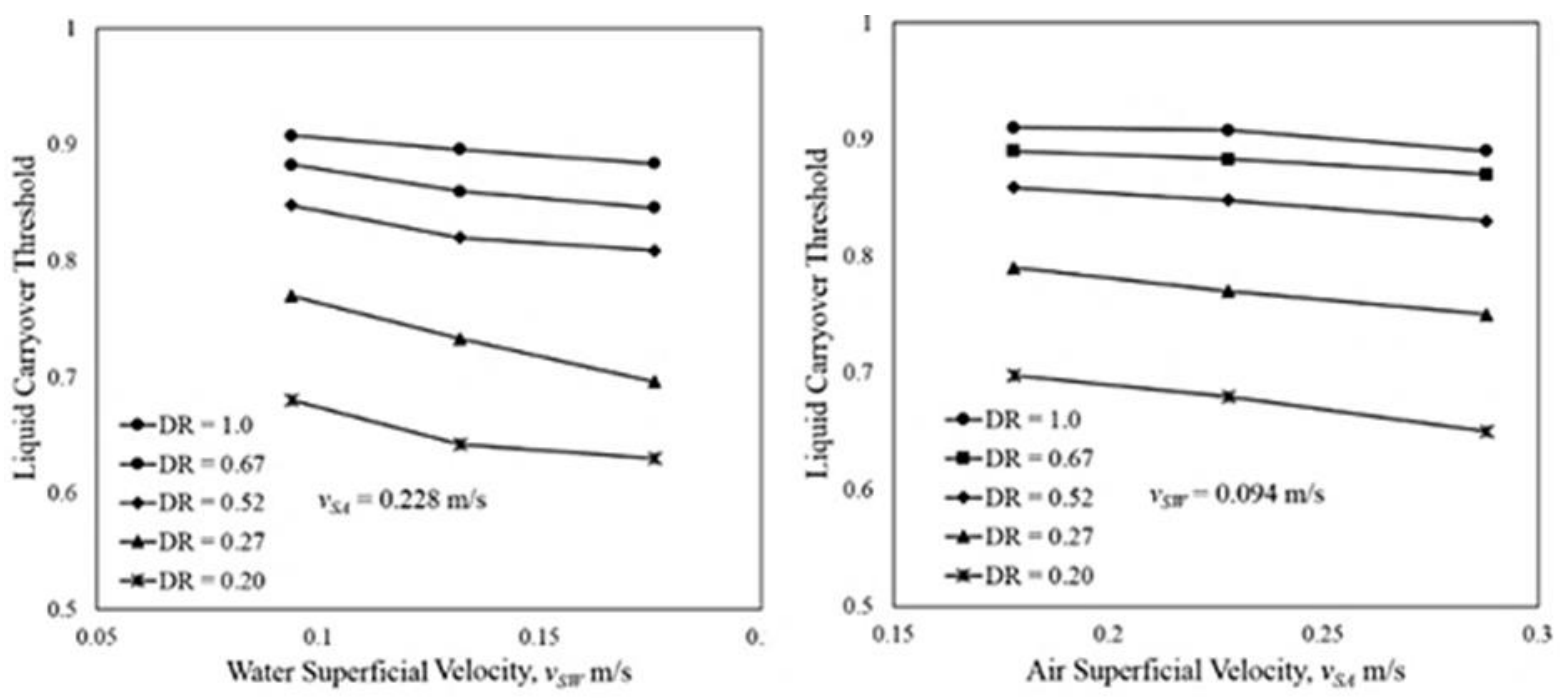

Fig. 19. Influence of liquid and gas (air) superficial velocity [43]

\subsubsection{Influence of flow regime}

Matsubara et al., [46] in their research debated the classification of flow regimes. Figure 20 is the visual illustration of the flow pattern along with the side view of the pipe.

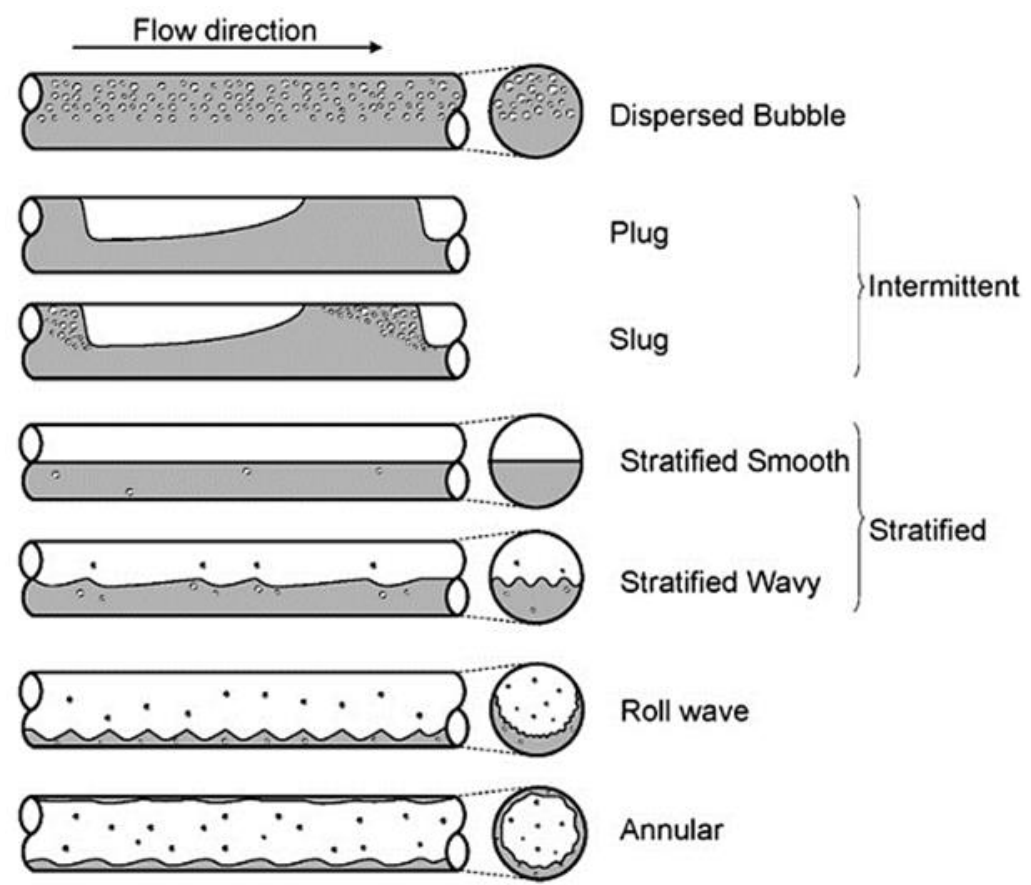

Fig. 20. Two-phase flow regimes in a horizontal pipe [46]

They concluded that changing gas or liquid superficial velocities, leads to different flow patterns. In dispersed bubble flow, separate gas bubbles are formed due to higher liquid superficial velocity. When these bubbles start to form with one another they form bigger bubbles that shape like a bullet. This genre of flow is known as plug or slug flow. However, at intermediate liquid superficial velocities, 
the liquid stays at the lower half of the pipe and gas being lighter flows towards the top (Figure 20). This type of flow is known as stratified smooth flow. As soon as we increase gas superficial velocity, the pressure from the gas makes waves within the liquid surface causing a wave-like flow known as stratified wavy flow. By further increasing the gas superficial velocity, liquid slips over to the side and forms a rolled wave shape due to the rounded inside surface of the pipe. In Annular flow, liquid flows at the top and the bottom of the pipe and gas flow freely at the center. This usually occurs for very high gas superficial velocities.

Taitel and Dukler [47] presented the flow regime map for horizontal T-junction for two-phase flow. It is noticeable that at lower gas and liquid superficial velocities the simplest form of flow is found i.e. stratified smooth flow (Figure 21). As we increase gas superficial velocity, waves start to form causing a resultant stratified wavy flow. However, for higher gas and liquid superficial velocity annular and slug flow are formed. Since liquid superficial velocity is very high in slug flow due to which slugs are formed which can cause vibrations in the pipeline. This consequence should be addressed in the flow loop because it can lead to damage to the instruments and T-junction itself.

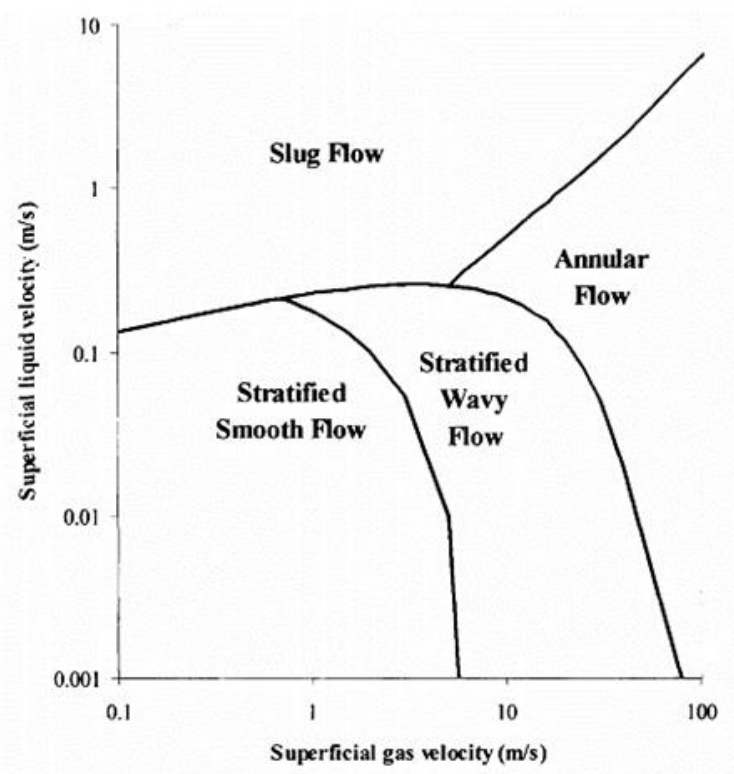

Fig. 21. Flow regime map for horizontal Tjunction [47]

\subsubsection{Series and parallel combinations of T-Junctions}

Baker et al., [34] worked on two T-junctions. The first T-junction having a vertically upward side arm whereas the second one having a vertically downward side arm. He used kerosene and air as the working fluids. The flow regime under consideration was stratified and slug flow.

Using 1 upward and 1 downward side arm T-junction in series can drastically increase the phase split (Figure 22). Downward side arm T-junction can eliminate the liquid slug effect. But for that to work properly, they used a pneumatically controlled solenoid valve which keeps the excess liquid inside the downward side arm and when the level goes up to a certain point, the valve opens and closes again to prevent gas to pass through it. This completely removed the slugging effect caused in slug flow. 


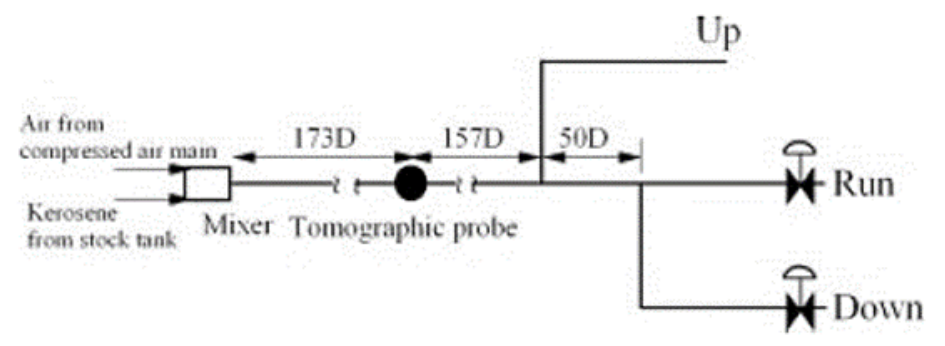

Fig. 22. Flow diagram by G. Baker using two T-junction in series [34]

Chen et al., [48] used three pipes as $s$ branch to the main arm (Figure 23). The branch pipes connect main arm to the upper horizontal arm. They used oil and water as the working fluid. The density of oil was lower than that of water, so it flows to the branched pipes and to the upper horizontal pipes. But water on the other hand has higher density so it stays in the horizontal pipe and get out from the water outlet. After simulation he concluded that the combination of T-junctions promotes the phase separation. They also suggested that it is mandatory that the pipe lengths should be long enough for both the liquids to settle at their corresponding positions during the flow.

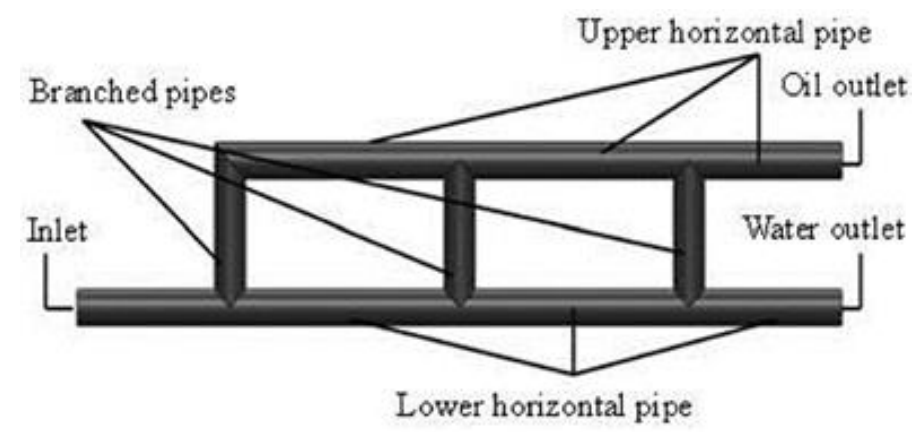

Fig. 23. Combination of T-junctions used by Chen et al., [48]

Azzopardi and Whalley [38] stated that phase separation in a T-junction doesn't only depend on the flow regime but it is highly dependent on the geometry of the junction also. Wren and Azzopardi [22] studied the geometrical effects of T-junction on flow separation phenomena (Figure 24). They used two T-junctions separately, one with side and main arm diameter of $0.125 \mathrm{~m}$ and the other one with the main arm of $0.125 \mathrm{~m}$ and side arm of $0.076 \mathrm{~m}$. The fluid stream taken into consideration entailed of water and air for Annular, wavy and stratified flows.
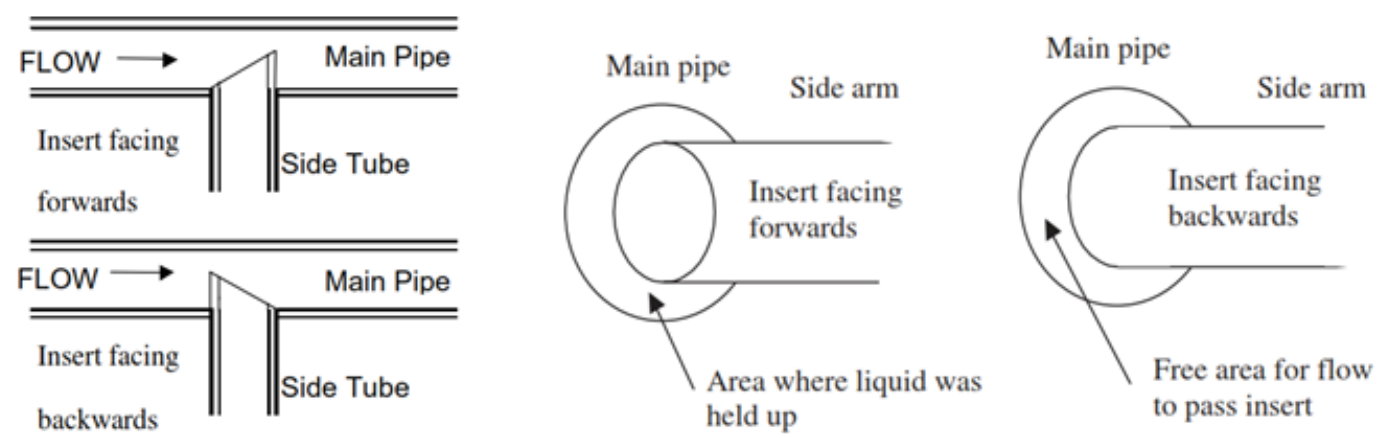

Fig. 24. Forward and backward insert positions in a T-junction [22] 
It is clearly seen from the Figure 25, that backward inserts almost completely block the liquid going to the side arm due to a blockage by side arm protrusion wall. However, forward insert slightly promoted the liquid fraction at the side arm due to the side arm inlet, in the way of the incoming liquid stream. However, having no protrusion at all showed intermediate results.

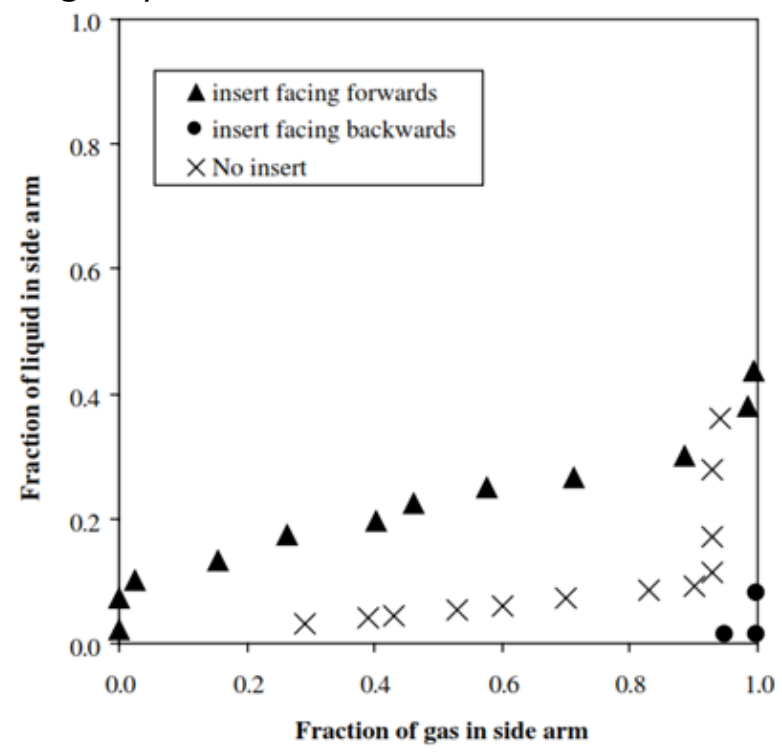

Fig. 25. Phase split data for annular flow [22]

\section{Conclusion}

It is described in several chemical, oil industries and reactor applications that T-junction plays a vital part in the phase separation redistribution. T-junction design methodology used in the industries is still not mature enough to fully predict the phase separation behavior.

This review manuscript intended to focus on some of the parameters that are of most importance when it comes to phase distribution. Parameters reviewed were geometrical parameters, phase superficial velocities, side arm modifications, a parallel configuration of the side arm and flow regime encountered. At the beginning of the manuscript, the problem is addressed with equations to fully understand the phase separation behavior. Then each influencing parameter is addressed to critically analyze the results from the literature

i. The criteria to calculate the phase separation is also reported in terms of "fraction of gas" and "fraction of liquid" in the side arm.

ii. Phase separation is highly dependent on the addressed parameters. It is found out that by decreasing the diameter ratio, phase separation increases. However, the latest developments in this concept address that by decreasing too much diameter ratio, this theory does not work. Thus, an optimum value of 0.67 diameter ratio was found to be true for good phase separation in terms of peak liquid carryover and liquid carryover threshold.

iii. Phase separation is highly dependent on phase superficial velocities. Separation efficiency can be increased by increasing liquid superficial velocity or decreasing gas superficial velocity.

iv. Slug flow is the most observed flow regime in the industries and also it is most turbulent. Phase separation is very unpredictable in this flow regime and not better as compared to stratified flow. Because in slug flow, gas superficial velocity is comparatively higher.

v. Side arm modifications are addressed from the literature. Although modifying the side arm improved phase separation but it is not high enough to recommend in the industries. More 
modifications and combinations of T-junctions are recommended to use to further analyze its effect.

\section{Acknowledgement}

The authors wish to acknowledge the research funding of Yayasan Universiti Teknologi PETRONAS under YUTP-015LC0-252 and Ministry of Higher Education Malaysia under Fundamental Research Grant Scheme FRGS/1/2019/TK03/UTP/02/10.

\section{References}

[1] Chen, Jinfang, Shuangfeng Wang, and Song Cheng. "Experimental investigation of two-phase distribution in parallel micro-T channels under adiabatic condition." Chemical engineering science 84 (2012): $706-717$. https://doi.org/10.1016/i.ces.2012.09.023

[2] Bai, Wanjin, Jiumin Xiao, Zhipeng Ru, Long Chen, and Xiaoxiao Xu. "Experimental study of the irreversible pressure loss coefficient at reduced T-junction with flat tube." Journal of Thermal Analysis and Calorimetry (2020): 1-9. https://doi.org/10.1007/s10973-020-09537-7

[3] Ny, G., N. Barom, S. Noraziman, and S. Yeow. "Numerical study on turbulent-forced convective heat transfer of Ag/Heg water nanofluid in pipe." J. Adv. Res. Mater. Sci 22, no. 1 (2016): 11-27.

[4] Siddegowda, Parashurama, Govindegowda Mundur Sannappagowda, Srinath Mandya Sridharamuthy, and Ramesha Devarahalli Kempegowda. "CFD Analysis of Dual-Phase Flows Inside Helically Coiled Tubes in Vapour Compression Micro-Refrigerator." CFD Letters 11, no. 2 (2019): 81-94.

[5] Sakr, Ismail M., Wageeh Ahmed El-Askary, Ashraf Balabel, and K. Ibrahim. "Computations of upward water/air fluid flow in vertical pipes." CFD letters 4, no. 4 (2012): 193-213.

[6] Azzopardi, B. J., and S. Rea. "Phase separation using a simple T-junction." In SPE Annual Technical Conference and Exhibition. Society of Petroleum Engineers, 2000. https://doi.org/10.2118/63040-MS

[7] Pao, William, Fakhruldin M. Hashim, and Low Huei Ming. "Computational Analyses of Passive Wet Gas Separation in Branched Piping." In MATEC Web of Conferences, vol. 13, p. 03009. EDP Sciences, 2014. https://doi.org/10.1051/matecconf/20141303009

[8] Chien, Sze-Foo. "Phase splitting of wet steam in annular flow through a horizontal branching tee." SPE Production \& Facilities 11, no. 02 (1996): 83-88. https://doi.org/10.2118/28542-PA

[9] Khattak, M. A., NS Mohd Ali, NH Zainal Abidin, N. S. Azhar, and M. H. Omar. "Common Type of Turbines in Power Plant: A Review." Journal of Advanced Research in Applied Sciences and Engineering Technology 3, no. 1 (2016): 77100.

[10] Ismail, H., A. A. Aziz, R. A. Rasih, N. Jenal, Z. Michael, and Azmi Roslan. "Performance of Organic Rankine Cycle Using Biomass As Source of Fuel." Journal of Advanced Research in Applied Sciences and Engineering Technology 4, no. 1 (2016): 29-46.

[11] Kharoua, N., and L. Khezzar. "Effects of Geometry, Temperature, and Inlet Conditions on the Flow Split in Spheroids Manifold." International Journal of Petrochemical Science \& Engineering $1 \quad$ (2016): 1-13. https://doi.org/10.15406/ipcse.2016.01.00022

[12] Yang, Lele, Jing Wang, Yong Ma, Sen Liu, Jun Tang, and Yongbing Zhu. "Oil-Water-Gas Three-Phase Separation in Multitube T-Junction Separators." Water 11, no. 12 (2019): 2655. https://doi.org/10.3390/w11122655

[13] Shoham, O., J. P. Brill, and Y. Taitel. "Two-phase flow splitting in a tee junction-experiment and modelling." Chemical Engineering Science 42, no. 11 (1987): 2667-2676. https://doi.org/10.1016/00092509(87)87017-3

[14] Azzi, A., A. Al-Attiyah, Liu Qi, W. Cheema, and B. J. Azzopardi. "Gas-liquid two-phase flow division at a micro-Tjunction." Chemical Engineering Science 65, no. 13 (2010): 3986-3993. https://doi.org/10.1016/i.ces.2010.03.037

[15] Conte, G., and B. J. Azzopardi. "Film thickness variation about a T-junction." International journal of multiphase flow 29, no. 2 (2003): 305-328. https://doi.org/10.1016/S0301-9322(02)00130-1

[16] Hong, K. C. "Two-phase flow splitting at a pipe tee." Journal of Petroleum Technology 30, no. 02 (1978): $290-296$. https://doi.org/10.2118/6530-PA

[17] Oranje, L. "Condensate behavior in gas pipelines is predictable." Oil and Gas Journal 32 (1973): 39-44.

[18] Yang, Bin, Wen Su, Shuai Deng, Li Zhao, and Pei Lu. "State-of-art of branching T-junction: Experiments, modeling, developing prospects and applications." Experimental Thermal and Fluid Science 109 (2019): 109895. https://doi.org/10.1016/i.expthermflusci.2019.109895

[19] Wren, Elisabeth Mary Katie. "Geometric effects on phase split at a large diameter T-junction." PhD diss., University of Nottingham, 2001. 
[20] Liang, Fachun, Hongfeng Zheng, Yuan Sun, and Lianmin Song. "Experimental investigation of phase split of gasliquid two-phase flow through small holes at the pipe wall." Experimental Thermal and Fluid Science 76 (2016): 330 341. https://doi.org/10.1016/i.expthermflusci.2016.03.029

[21] Marti, S., and O. Shoham. "A unified model for stratified-wavy two-phase flow splitting at a reduced T-junction with an inclined branch arm." International journal of multiphase flow 23, no. 4 (1997): 725-748. https://doi.org/10.1016/S0301-9322(97)82477-9

[22] Wren, E., and B. J. Azzopardi. "Affecting the phase split at a large diameter T-junction by using baffles." Experimental thermal and fluid science 28, no. 8 (2004): $835-841$. https://doi.org/10.1016/i.expthermflusci.2003.12.017

[23] Azzopardi, B. J. "The effect of side arm diameter on phase split at T-junctions." In SPE Annual Technical Conference and Exhibition. Society of Petroleum Engineers, 1999. https://doi.org/10.2118/56707-MS

[24] Rea, S., and B. J. Azzopardi. "The split of horizontal stratified flow at a large diameter T-junction." Chemical Engineering Research and Design 79, no. 4 (2001): 470-476. https://doi.org/10.1205/026387601750282409

[25] Syahir, M., and William Pao. "Experimental Investigation of Liquid Carryover in Inclined T-Junction.".

[26] Zhang, Jian, Qi-lin Wu, Shuo Liu, and Jing-yu Xu. "Investigation of the Gas-Liquid Two-Phase Flow and Separation Behaviors at Inclined T-Junction Pipelines." ACS omega 5, no. 34 (2020): 21443-21450. https://doi.org/10.1021/acsomega.0c01805

[27] Wang, Li-yang, Ying-xiang Wu, Zhi-chu Zheng, Jun Guo, Jun Zhang, and Chi Tang. "Oil-water two-phase flow inside T-junction." Journal of Hydrodynamics 20, no. 2 (2008): 147-153. https://doi.org/10.1016/S1001-6058(08)60040-2

[28] Mohamed, M. A., H. M. Soliman, and G. E. Sims. "Experimental investigation of two-phase flow splitting in an equalsided impacting tee junction with inclined outlets." Experimental Thermal and Fluid Science 35, no. 6 (2011): 11931201. https://doi.org/10.1016/i.expthermflusci.2011.04.006

[29] Yang, Limin, Jiahao Wang, Zhenying Zhao, Shengbo Xu, Barry J. Azzopardi, and Hong Wang. "Phase separation of gas-liquid two-phase stratified and plug flows in multitube T-junction separators." AIChE Journal 63, no. 6 (2017): 2285-2292. https://doi.org/10.1002/aic.15552

[30] Baker, Glen. "Separation and control of gas-liquid flows at horizontal T-junctions." PhD diss., Nottingham University, 2003.

[31] Walters, Lori C. "Two-phase pressure drop and phase distribution at horizontal tee junctions: the effect of branch diameter." (1994).

[32] Ismail, Ahmad Shamsul Izwan, Issham Ismail, Mansoor Zoveidavianpoor, Rahmat Mohsin, Ali Piroozian, Mohd Shahir Misnan, and Mior Zaiga Sariman. "Experimental investigation of oil-water two-phase flow in horizontal pipes: Pressure losses, liquid holdup and flow patterns." Journal of Petroleum Science and Engineering 127 (2015): 409-420. https://doi.org/10.1016/i.petrol.2015.01.038

[33] Chen, Jinfang, Shuangfeng Wang, Hongfeng Ke, Songheng Cai, and Ying Zhao. "Gas-liquid two-phase flow splitting at microchannel junctions with different branch angles." Chemical Engineering Science 104 (2013): 881-890. https://doi.org/10.1016/i.ces.2013.10.013

[34] Baker, G., W. W. Clark, B. J. Azzopardi, and J. A. Wilson. "Transient effects in gas-liquid phase separation at a pair of T-junctions." Chemical engineering science 63, no. 4 (2008): 968-976. https://doi.org/10.1016/j.ces.2007.10.035

[35] Mak, C. Y., N. K. Omebere-lyari, and B. J. Azzopardi. "The split of vertical two-phase flow at a small diameter Tjunction." Chemical engineering science 61, no. 19 (2006): 6261-6272. https://doi.org/10.1016/j.ces.2006.05.039

[36] Wren, E., G. Baker, B. J. Azzopardi, and R. Jones. "Slug flow in small diameter pipes and T-junctions." Experimental Thermal and Fluid Science 29, no. 8 (2005): 893-899. https://doi.org/10.1016/i.expthermflusci.2005.01.004

[37] Seeger, W., J. Reimann, and U. Müller. "Two-phase flow in a T-junction with a horizontal inlet. Part I: Phase separation." International journal of multiphase flow 12, no. 4 (1986): 575-585. https://doi.org/10.1016/03019322(86)90061-3

[38] Azzopardi, BJ T., and P. B. Whalley. "The effect of flow patterns on two-phase flow in a T junction." International Journal of Multiphase Flow 8, no. 5 (1982): 491-507. https://doi.org/10.1016/0301-9322(82)90020-9

[39] Azzopardi, B. J. "The effect of the side arm diameter on the two-phase flow split at a "T" junction." International journal of multiphase flow 10, no. 4 (1984): 509-512. https://doi.org/10.1016/0301-9322(84)90059-4

[40] Saieed, Ahmed, William Pao, Buddhika Hewakandamby, Barry J. Azzopardi, David A. Wood, and Hafiz M. Ali. "Experimental investigation on the effect of diameter ratio on two-phase slug flow separation in a TJunction." Journal of Petroleum Science and Engineering $170 \quad$ (2018): $139-150$. https://doi.org/10.1016/j.petrol.2018.06.033

[41] Memon, Zeeshan Qadir, William Pao, Fakhruldin M. Hashim, and Hafiz M. Ali. "Experimental investigation of twophase separation in T-Junction with combined diameter ratio." Journal of Natural Gas Science and Engineering 73 (2020): 103048. https://doi.org/10.1016/i.jngse.2019.103048 
[42] Hart, J., P. J. Hamersma, and J. M. H. Fortuin. "Phase distribution during gas-liquid flow through horizontal dividing junctions." Nuclear engineering and design 126, no. 3 (1991): 293-312. https://doi.org/10.1016/00295493(91)90022-A

[43] Saieed, Ahmed, William Pao, and Fakhruldin M. Hashim. "Effect of T-junction diameter ratio on stratified-wavy flow separation." Journal of Natural Gas Science and Engineering $51 \quad$ (2018): $223-232$. https://doi.org/10.1016/i.jngse.2018.01.015

[44] Ejaz, Faheem, William Pao, Mohammad Shakir Nasif, Ahmed Saieed, Zeeshan Q. Memon, and Md Nuruzzaman. "A review: Evolution of branching T-junction geometry in terms of diameter ratio, to improve phase separation." Engineering Science and Technology, an International Journal (2021). https://doi.org/10.1016/i.jestch.2021.02.003

[45] Das, G., P. K. Das, and B. J. Azzopardi. "The split of stratified gas-liquid flow at a small diameter Tjunction." International journal of multiphase flow 31, no. $4 \quad$ (2005): 514-528. https://doi.org/10.1016/i.ijmultiphaseflow.2005.01.009

[46] Matsubara, Hiroaki, and Kiyoshi Naito. "Effect of liquid viscosity on flow patterns of gas-liquid two-phase flow in a horizontal pipe." International Journal of Multiphase Flow 37, no. 10 (2011): $1277-1281$. https://doi.org/10.1016/i.ijmultiphaseflow.2011.08.001

[47] Taitel, Yehuda, Dvora Bornea, and A. E. Dukler. "Modelling flow pattern transitions for steady upward gas-liquid flow in vertical tubes." AIChE Journal 26, no. 3 (1980): 345-354. https://doi.org/10.1002/aic.690220105

[48] Chen, Jian-lei, Li-min He, Xiao-ming Luo, Hai-tao Bai, and Yan-hai Wei. "Simulation of oil-water two phase flow and separation behaviors in combined T junctions." Journal of Hydrodynamics 24, no. 6 (2012): 848-857. https://doi.org/10.1016/S1001-6058(11)60312-0

[49] B.J. Azzopardi, MultiPhase Flow-Department of Chemical and Environmental Engineering, University of Nottingham, UK, I (n.d.). 